FILOLOGÍA FRANCESA 



\title{
EL COMPONENTE INTERCULTURAL EN EL ESCENARIO PROFESIONAL TURÍSTICO Y SU INCIDENCIA EN LOS MANUALES DEL FRANCÉS PARA FINES ESPECÍFICOS
}

\author{
Severina Álvarez GonZÁlez \\ Universidad de Extremadura \\ severinaag@unex.es
}

\section{RESUMEN}

El objetivo del presente artículo es presentar la interculturalidad como un factor esencial en la enseñanza-aprendizaje del Francés para Fines Específicos (FOS) y verificar si está presente en los tres manuales elegidos para nuestra investigación: Les Métiers du Tourisme, Le Français du Tourisme y tourisme.com. Se trata, en definitiva, de averiguar si éstos proporcionan los conocimientos, destrezas y habilidades interculturales que capaciten al aprendiz para actuar como experto, en lengua extranjera francesa, en el marco profesional turístico.

PALABRAS CLAVE: Interculturalidad; manuales; enseñanza-aprendizaje; sector turístico.

RÉSUMÉ

L'objectif de cet article consiste à présenter l'interculturalité comme un facteur essentiel dans l'enseignement-apprentissage du Français sur Objectifs Spécifiques (FOS) et de vérifier s'il est présent dans les trois manuels choisis pour notre recherche: Les Métiers du Tourisme, Le Français du Tourisme et tourisme.com.

Il s'agit, en définitive, de vérifier si ceux-ci fournissent à l'apprenti les connaissances et l'habileté interculturelles nécessaires pour agir comme expert en langue étrangère (français) dans le cadre professionnel touristique.

MoTS CLÉs: Interculturalité; manuels; enseignement-apprentissage; secteur touristique. 


\section{INTRODUCCIÓN}

El turismo es una de las primeras actividades económicas en el mundo. Si se tienen en cuenta los efectos directos e indirectos del turismo, este sector da empleo a 220 millones de personas y genera más del 10\% de la riqueza mundial (WTTC). El sector turístico se reivindica como uno de los motores más significativos de la economía española pues son muchas las áreas relacionadas de forma directa o indirecta con esta actividad. Las últimas estadísticas sitúan a nuestro país entre los tres primeros del mundo, en número de turistas extranjeros, con más de 55 millones de turistas anuales, por detrás de Francia y por delante de Estados Unidos. España se ha convertido en uno de los destinos mundiales del turismo internacional (Reino Unido, Alemania y Francia concentran el 61\% de los turistas visitantes), e indudablemente el sector turístico constituye uno de los pilares más firmes de la economía española.

Asimismo, el turismo es una fuente generadora de divisas, de empleos y es un factor de expansión del mercado nacional. Este sector se distingue así como el que más crece. Del mismo modo, España se encuentra en una posición de liderazgo en la recepción de turistas no residentes superando en el año 2005 los 55,6 millones.

¿En qué consiste el turismo? ¿Cuál es su significado? Maximiliano Korstanje (2008:1) nos aporta una interesante definición del término «turismo» al definirlo en los siguientes términos:

Toda forma moderna de ocio (comercializado o gratuito) que implique un desplazamiento temporario y consecuente retorno satisfaciendo así necesidades psico-sociales específicas de descanso, relajación y afirmación de estatus en espacios socialmente determinados y destinados para tal fin.

A partir de estas palabras, se desprende que dicho término lleva implícito el desarrollo de actividades de naturaleza recreativas, comerciales o gratuitas. Por nuestra parte, el turismo supone además una actividad que implica el contacto directo entre culturas y todo lo que ello incluye folklore, costumbres, gastronomía, normas, etc. permitiendo, de este modo, valorar los propios recursos existentes y contrastar otras formas de pensar. Supone, en definitiva, el enriquecimiento del conjunto de la sociedad. En este sentido, el agente turístico se convierte en un mediador intercultural y adquiere un papel primordial en la actividad turística.

Por ello, los idiomas, que a lo largo de los años han tenido unas finalidades prácticas, tienen una importancia significativa y su presencia en el sector turístico ha de ocupar un lugar relevante. El dominio de una lengua extranjera es indispensable para intervenir eficazmente en el sector, un segundo idioma es a menudo necesario, y conocer un tercer idioma resulta frecuentemente decisivo para acceder al mundo laboral en ese ámbito. Los idiomas son, por lo tanto, claves en la formación de los futuros profesionales del sector turístico al convertirse en un recurso primordial para potenciar no solamente los aspectos gramaticales y lingüísticos sino también culturales y sociales de una nueva cultura.

\section{JUSTIFICACIÓN DEL APRENDIZAJE DE UNA LENGUA EXTRANJERA EN EL SECTOR TURÍSTICO}

Los conocimientos adecuados de una lengua extranjera en el sector turístico van a contribuir a estimular los siguientes aspectos en los profesionales: 
- El personal cualificado en lenguas extranjeras complementará sus competencias laborales en el puesto de trabajo que desempeña. No sólo estará capacitado para resolver asuntos de tipo profesional (reservas, anulaciones, reclamaciones, información,...) sino también estará habilitado para dirigirse y conversar en la lengua del turista extranjero.

- El personal cualificado en lenguas extranjeras contribuirá a la satisfacción de los clientes extranjeros, con una adecuada comunicación, pues serán atendidas y complacidas las expectativas de éstos de manera más eficiente.

- El personal cualificado en lenguas extranjeras proporcionará una sensación satisfactoria en el cliente al final de su estancia y su deseo de volver, será el éxito de su misión.

El conocimiento de una o varias lenguas extranjeras en el sector profesional turístico resulta ser un elemento potenciador para llevar a buen término una transacción comercial de esta índole. Sin embargo, pensamos que la enseñanza-aprendizaje de una lengua extranjera ha de llevarnos un poco más allá de lo puramente lingüístico y aportarnos todo el bagaje cultural de esta nueva lengua pues, al igual que Dale y Oliver (2000) somos de la opinión de que un conocimiento básico de las diferencias entre culturas ayuda al profesional del turismo a hacer preguntas apropiadas en cada caso y a adaptarse a las necesidades específicas de cada cliente. En esta misma línea, autores como Suárez y Moss (2000) sitúan en un mismo nivel los aspectos culturales y lingüísticos de una lengua extranjera.

De las opiniones vertidas por los autores mencionados se desprende que la integración del aprendizaje lingüístico y cultural facilita la comunicación y la interacción. Por lo tanto y llegado a este punto, resulta imprescindible plantear o enfocar, en nuestras aulas de idiomas, una enseñanza-aprendizaje que asimile ambos elementos de manera que repercuta satisfactoriamente en los futuros profesionales del turismo.

\section{EL ENFOQUE INTERCULTURAL EN EL AULA DE LENGUAS PARA FINES ESPECÍFICOS}

La primera finalidad para el aprendizaje de una lengua extranjera, en nuestro caso para fines específicos, no es otra que la de comunicarse en un entorno profesional. La comunicación pone en juego a todo el ser humano, es decir, todas las aptitudes de la persona. No se limita simplemente a una mera transmisión de información pues esta situación de comunicación es mucho más compleja, teniendo en cuenta que existen operaciones cognitivas que nos permiten no sólo interpretar el universo simbólico en el que nos encontramos sino también construir un sentido que sea susceptible de ser interpretado. Cada lengua transmite una cultura y una historia y es, por esta razón, que el aprendizaje de una lengua extranjera nos brinda la posibilidad de abrir una ventana sobre una nueva cultura y contemplar una visión del mundo diferente. Por tanto, si queremos aprender otra lengua, hablada por otros pueblos, tenemos que impregnarnos de su cultura, de su forma de vivir y pensar. Christine Tagliante (1994:68) corrobora esta idea al indicar que:

Enseigner une langue, ce n'est pas seulement enseigner à communiquer: par leur histoire et leur étymologie, les mots mêmes que l'on emploie, les structures, les expressions, véhiculent un passé, une culture, une civilisation. 
La interculturalidad es un proceso de interacción social que impulsa procesos de intercambios y, además, propone una comunicación horizontal, donde ninguno de los interlocutores se siente superior al otro. Asimismo, permite salirse de su cultura, admitir y respetar al otro como su alter ego en esa lengua, y saber que nosotros existimos y somos diferentes a él, en la medida que él existe y es diferente a nosotros. Pero, tenemos que considerar su existencia, para poder dar sentido a nuestra existencia. La interculturalidad consiste, en definitiva, en el conocimiento y reconocimiento de lo propio y de lo ajeno. Esta es la razón por la cual la interculturalidad va ligada hoy en día al aprendizaje de una lengua extranjera, ya que pone el acento sobre los intercambios entre iguales en una cultura nueva. Louis Porcher (2004:118) ahonda en este aspecto al exponer la siguiente reflexión:

Quand on apprend une langue étrangère, c'est l'interculturel qui est en jeu [...]. Certes, on vise une communication, donc une capacité technique, mais qui ne saurait être purement linguistique et formelle. [...] On cherche aussi à respecter chacune des cultures, des croyances, chacun des modes de vie, à aller vers un métissage possible sans abandon de son identité. Apprendre une langue étrangère c'est affirmer à la fois sa propre identité et celle de l'étranger en allant vers les conditions d'une coopération et en se donnant les moyens d'éviter les affrontements.

Nos parece igualmente interesante, la aportación de Jean Claude Beacco y alii (2010) al considerar la competencia intercultural como un mediador empático entre culturas diferentes.

Así pues, la orientación intercultural en la enseñanza-aprendizaje de las lenguas no hay que entenderla como un nuevo enfoque o método, sino que se trata de reconsiderar y revisar el concepto universal de competencia comunicativa. Por ejemplo, hoy sabemos que actos de habla como «saludarse» o «presentarse» que se pensaban universales, en realidad no lo son. En esto y en otros actos de habla hay diferencias significativas que pueden dar lugar a malentendidos cuando dos diferentes culturas se encuentran.

El enfoque intercultural, por lo tanto, cobra una importancia relevante en la enseñanza-aprendizaje de la lengua extranjera, en nuestro caso francés, en el entorno profesional turístico en la medida en que, tal y como apunta Calvi (2001:299-303) todo profesional del turismo debe conocer las distintas normas culturales y por ello ha de tener presente los siguientes factores:

1. Identificación y superación de los estereotipos relativos a la cultura extranjera.

2. Conciencia intercultural, entendida como la capacidad de reconocer las características de una cultura extranjera comparándola con la propia y con otras conocidas.

3. Competencia comunicativa y pragmática, es decir, el conocimiento de los comportamientos sociales y capacidad de actuación en diversas situaciones interactivas.

4. Conocimiento de diversas disciplinas como el arte, la geografía o la gastronomía y la capacidad de relacionarlos con los elementos lingüísticos pertinentes.

Byram y Fleming (2001:14) por su lado, apuntan que el enfoque intercultural propicia los siguientes elementos: 
a. La integración del aprendizaje lingüístico y cultural para facilitar la comunicación y la interacción.

b. La comparación de otros con uno mismo para estimular la recapacitación y el cuestionamiento (crítico) de la cultura central en la que se socializan los alumnos.

c. Un cambio de perspectiva que emplea procedimientos psicológicos de socialización.

d. El potencial de la enseñanza de idiomas para preparar a los alumnos a efectuar encuentros y comunicarse en culturas y sociedades diferentes de las que normalmente se asocian con el idioma que están estudiando.

Como en todo manual, en los de lengua extranjera en ámbitos profesionales más concretamente turísticos confluye una multiplicidad de componentes. Choppin (1980:1) establece que además de ser un objeto, cuya concepción, comercialización y distribución evoluciona con las transformaciones editoriales y socio-económicas, un manual es también un vehículo de valores tanto como un instrumento pedagógico y un campo de aplicación de determinadas opciones metodológicas.

El sesgo marcadamente profesional de una lengua extranjera para fines específicos, como son los turísticos, implica que su enseñanza-aprendizaje no se vuelca tanto en la lengua sino en la realización de tareas que el hablante llevará a cabo en el idioma objeto de estudio, entendiendo por tarea, siguiendo el Marco común europeo de referencia para las lenguas (Consejo de Europa 2002:155), «la activación estratégica de competencias específicas, con el fin de llevar a cabo una serie de acciones intencionadas en un ámbito concreto con un objetivo claramente definido y un resultado específico». Sin dejar de abordar los aspectos puramente linguísticos, al realizar las tareas o proyectos también se ha de abordar la «cultura profesional» (Centro Virtual Cervantes 2011:1), es decir, el conjunto de normas o reglas, implícitas o explícitas, vigentes en el sector y que también están muy presentes en la lengua meta. En esa línea se manifiestan Carras, Tolas et alii (2007:21), quienes consideran determinante conocer y respetar los códigos propios de un sector profesional para realizar eficazmente las tareas efectuadas en lengua extranjera; cuestiones como el comportamiento y la actitud ante diversas situaciones profesionales frecuentes, orales y escritas (manejar el código gestual, saludar, formular una invitación, expresar el desacuerdo, establecer turnos de habla en una negociación, producir documentación profesional, etc.), deben ser objeto de enseñanza-aprendizaje en el ámbito turístico, ateniéndose siempre a unas normas de interacción y de mediación propias.

Partiendo, pues, del principio de que aprender una nueva lengua significa entrar en contacto con una nueva lengua-cultura, vivir esa lengua, intentar pensar como sus hablantes nativos, creemos que no sólo es importante comunicar, sino también adecuar lo que se quiere comunicar a las reglas sociolingüísticas relacionadas al contexto.

Dentro del entorno turístico que nos ocupa, el conocimiento de la cultura del otro se convierte en un elemento de máxima importancia en la medida en que al viajar al extranjero, al observar el comportamiento de los extranjeros visitantes de nuestro país o al mantener contactos profesionales con los turistas de países y culturas diferentes, tendemos, en la mayoría de los casos, a juzgar en función de lo que conocemos, desde el punto de vista de nuestras costumbres y creencias. Moreno García (2000:1) ahonda en esta idea con estas palabras al apuntar la siguiente observación: 
Y por ello solemos emitir juicios en términos de lo que los otros no hacen en relación con lo que para nosotros es normal, o bien consideramos raro, chocante y, en el peor de los casos, absurdo, lo que para los observados es habitual.

De estas palabras se desprende que el choque cultural puede llevar a malentendidos que podrían repercutir negativamente, en nuestro caso, en el trabajo del profesional del sector, de ahí, la necesidad de adquirir un conocimiento sólido de la cultura del otro con el fin de alcanzar una comunicación sin interferencias culturales.

Esta presentación que acabamos de exponer en torno a la importancia del elemento cultural e intercultural en el ámbito turístico nos ha llevado a reflexionar y analizar sobre el lugar que ocupa la cultura en los manuales de FOS. Este aspecto ha sido siempre una constante en nuestras investigaciones porque somos de la opinión de que la presencia cultural es un factor esencial en la comunicación por promover valores humanos, universales, nacionales, éticos,... El aprendiz tiene que ser consciente de que forma parte de un entorno cultural determinado, pero que al mismo tiempo ha de abrirse a otras culturas en Europa y en el mundo. De ahí el interés de verificar, y este es el objetivo del presente trabajo, cómo se aborda la enseñanza del francés turístico en los diferentes manuales utilizados en nuestras aulas de idiomas. Se trata de averiguar si dichos manuales proporcionan los conocimientos, destrezas, habilidades y herramientas que capaciten al aprendiente para actuar como experto en lengua extranjera, en nuestro caso francés, dentro del amplio marco profesional turístico. En último término, el objetivo planteado es el de comprobar si los manuales elegidos para nuestra investigación cumplen con las exigencias impuestas por el auge de este importante sector que no es otro que el de establecer unas relaciones comerciales satisfactorias con clientes de otras nacionalidades, culturas,...

\section{CORPUS ELEGIDO PARA LA INVESTIGACIÓN}

Los manuales de francés para fines específicos que presentamos a continuación y que hemos elegido para formar parte de nuestro corpus son aquellos que se han utilizado, en un primer momento, en la Diplomatura de Turismo y en la actualidad, en el Grado de Turismo de la Facultad de Comercio, Turismo y Ciencias Sociales de la Universidad de Oviedo. La elección de los manuales citados se debe principalmente a que estas obras se adaptan a los niveles y a los contenidos requeridos en la titulación. Esta es la razón fundamental por la que, en su momento, optamos por implantar dichos manuales, y no otros, para la impartición de nuestras asignaturas ${ }^{1}$ :

- Les Métiers du Tourisme (Chantelouve, Corbeau y Dubois): este manual publicado en 1991 está concebido para estudiantes que hayan cursado más de 200 horas de francés, lo que corresponde a un nivel A2+.

\footnotetext{
${ }^{1}$ Quisiéramos puntualizar que el mercado editorial correspondiente al Francés turístico es, en nuestra opinión, bastante restringido y los manuales existentes son de difícil adaptabilidad en nuestras aulas debido, principalmente, a su falta de especificidad turística.
} 


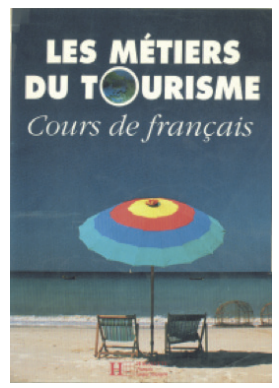

Figura 1. Les Métiers du Tourisme (Chantelouve, Corbeau y Dubois).

- Le Français du Tourisme (Calmy) publicado en 2004 se concibe para estudiantes que hayan cursado 200 horas del idioma, lo que corresponde a un nivel A2 2 .

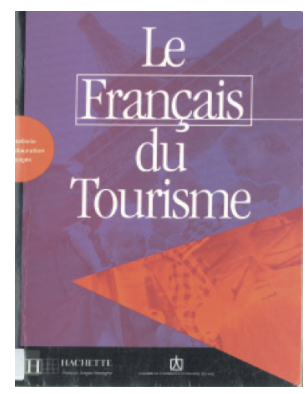

Figura 2 Le Français du Tourisme (Calmy).

- tourisme.com (Corbeau, Dubois y Penfornis) publicado en el 2004 es el más reciente de los manuales analizados, destinado a alumnos «faux-débutants», con 60 horas de francés general, y que corresponde a un nivel A1.

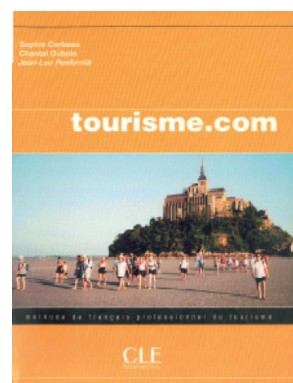

Figura 3. tourisme.com (Chantelouve, Corbeau y Dubois).

${ }^{2}$ A pesar de que ambos manuales exigen 200 horas de idioma, éstos responden a un nivel diferente de conocimiento. En «Les Métiers du Tourisme» se requiere, por parte del estudiante, una mayor capacidad lingüística para hacer diálogos en situaciones profesional que en «Le Français du Tourisme»y «tourisme.com». 
A modo de presentación de estos tres manuales y de una manera general, podríamos apuntar que en todos ellos, encontramos temas comunes de ámbito turísticos como podrían ser la agencia de viaje, el hotel, los profesionales turísticos, los medios de transporte, el guía turístico, la promoción turística,... pero utilizando niveles lingüísticos diferentes en cada uno de ellos.

Nuestro cometido, con este artículo, no es otro que el de comprobar si en dichos manuales se alude solamente al sector turístico francés o si por el contrario aparecen elementos turísticos de países cuya lengua común es el francés o entornos turísticos de países de lenguas y culturas diferentes. En definitiva, pretendemos constatar si en dichos manuales se contemplan elementos interculturales que permitan al estudiante adquirir unas competencias adecuadas para desarrollarse óptimamente en el sector profesional turístico. Como ya hemos señalado más arriba, pensamos que los futuros profesionales deben conocer la diversidad cultural de los países para poder, de este modo, solventar problemas de comunicación tanto con los clientes como con los profesionales del sector. De igual modo, compartimos totalmente la opinión de Calvi (2001:300) al decir que el estudiante de cualquier lengua extranjera debe adquirir una competencia lingüística basada en: «no sólo en el saber técnico de especialidad sino también en la especificidad cultural de los principales destinos turísticos en los que se habla la lengua en cuestión»

\section{MÉTODO DE ANÁLISIS APLICADO}

Para llevar a cabo nuestra investigación en relación a la presencia intercultural en estos manuales tomamos, como punto de partida, una serie de interrogante señalados por la profesora María Silvina Paricio Tato (2005) al analizar la dimensión cultural de los manuales generalistas y que podría ayudarnos a elaborar nuestros propios parámetros interculturales.

Esta autora reflexionó en torno a los siguientes aspectos:

- ¿Constituye la cultura un simple escenario que sirve de telón de fondo a los aprendizajes lingüísticos, o bien se integran como parte significativa de éstos?

- ¿Obedece la presentación de la cultura extranjera a una intencionalidad formativa?

- ¿Se incluyen referencias a la cultura de origen del alumno para contrastarla con la cultura meta?

- ¿Se ofrece una presentación de la cultura centrada en un único país, el más representativo de la lengua meta, o hay referencia a la pluralidad de países en los que se habla esa lengua extranjera?

- ¿Se presentan situaciones y se abordan temáticas relacionadas con los intereses y aficiones de los jóvenes?

- ¿Se invita al estudiante a profundizar en la cultura del país proponiéndole documentación complementaria (prensa, revistas, películas, ...)?

- ¿Se incluyen documentos auténticos?

- ¿El contenido de las actividades hace referencia a aspectos socio-culturales tales como: los hábitos de la vida cotidiana, la vida política, la religión, la cortesía, la familia, la escuela, los valores,...? 
- ¿Las actividades atienden a factores afectivos, cognitivos, situacionales?

- ¿Las actividades requieren la opinión del estudiante?

Con la ayuda de estos interrogantes elaboramos tres parámetros interculturales que, a nuestro juicio, deberían estar integrados en cualquier manual FOS para estimular las interrelaciones socio culturales entre las dos lenguas, factor fundamental en las relaciones profesionales turísticas.

\subsection{Parámetros interculturales}

Para este estudio, nos hemos centrado en tres elementos que, para la autora de este artículo, son esenciales para alcanzar unas competencias interculturales en el entorno profesional turístico:

- La inclusión de la identidad ${ }^{3}$ y las características culturales de la lengua meta y de la lengua del aprendiz. Este parámetro resulta esencial en el aprendizaje de una lengua extranjera en la medida en que los conceptos de identidad y de cultura nos aportan una información muy valiosa acerca de los aspectos sociales, religiosos, morales,... de la nueva lengua cultura. Además, ambos son convergentes puesto que el primero se construye a partir de materiales culturales. La identidad y las características culturales adquieren una dimensión significativa en la enseñanza de lenguas para fines específicos debido a que el conocimiento socio-cultural que nos brindan dichos conceptos permite al profesional del turismo interrelacionarse de forma óptima evitando, de este modo, «choque culturales» que podrían ocasionar pérdidas de transacciones comerciales. Por lo tanto, reflejar en un manual para fines específicos, en nuestro caso francés para el turismo, los aspectos de identidad y cultura francesa y española confieren al aprendiz una visión diferenciadora de las dos culturas. Con relación a esta idea, Immanuel Wallerstein (1992:31) ya indicaba que una de las funciones casi universalmente atribuida a la cultura es la de diferenciar a un grupo de otros grupos. Pero además, ambos aspectos nos proporcionan elementos simétricos, convergentes entre las dos lenguas culturas lo que despierta, en un gran número de estudiantes, un sentimiento de acercamiento e incluso de empatía hacia la nueva lengua-cultura. Este parámetro nos permite combinar objetivos pragmáticos, cognitivos y afectivos. Combinación que, por otro lado, nos parece fundamental puesto que el fin esencial de un manual al uso es el de ofrecer a los estudiantes las herramientas necesarias para desarrollarse adecuadamente en el entorno profesional.

- La comparación de las dos lenguas-culturas y la eliminación de la jerarquización: las dos lenguas-cultura en un mismo plano. Los manuales de francés para fines específicos han de reflejar las dos culturas para poder así compararlas y reconocer en la otra lengua-cultura lo común y lo diferente. Asimismo, somos de la opinión de que si se

${ }^{3}$ Queremos puntualizar que el término identidad tiene origen psicológico y en un sentido básico significa aquello que es propio e inalienable de una persona; por extensión identidad cultural viene a ser lo que es propio e inalienable de una cultura. 
estimula la cercanía entre la nueva lengua y la propia, este proceso puede favorecer positivamente la adquisición de una L2 en la medida en que esto permite crear una sensibilización del estudiante hacia su propia cultura y una predisposición hacia la aceptación y valoración de otra cultura. Así pues, una cultura no se comprende más que con relación a otras. Aprender a comparar dentro de un contexto determinado ha de formar parte del diseño de actividades propuestas en los manuales ya que de este modo será posible comparar conceptos, hechos, actitudes, situaciones. Por lo tanto, el enfoque intercultural anima a comparar el propio mundo con el ajeno y a reflexionar sobre lo que se percibe como diferente (Melero Abadía, 2000) y por ende, la comparación de las dos lenguas- culturas nos ayuda a vencer la imagen preconcebida de actitudes de prejuicio, marginación y menosprecio. Por lo tanto, la presencia de las dos culturas ha de formar parte de los contenidos de los manuales de francés para el turismo con el propósito de que los futuros actores del sector tengan la oportunidad no sólo de conocerse mejor sino también de poder verse reflejado en la cultura meta.

- La verificación de los estereotipos ${ }^{4}$ y su superación en ambas lenguas-culturas. Los estereotipos son casi siempre el resultado de una comparación hecha desde un solo punto de vista. Asimismo, comparar sin más reflexión lleva al estereotipo. Los estereotipos pueden resultar elementos útiles para un primer contacto con una nueva cultura. Herrero (2006) ahondando en esta idea al indicar que desempeña una función «constructiva porque es un punto de apoyo para nuestra percepción de la compleja realidad del mundo y porque facilita nuestro contacto y relación con los demás por el hecho de compartir esquemas cognitivos y lingüísticos comunes». Por otro lado, para Lamo de Espinosa (1993:13), el estereotipo se define como un mapa cognitivo que simplifica una realidad poco conocida para hacerla manejable y comprensible. Además, el estereotipo ofrece una imagen de grupo, de comunidad aunque, en algunas ocasiones, se puede quedar corto en cuanto a la imagen de la cultura reflejada e incluso puede mostrar realidades equivocadas de grupo social ${ }^{5}$. En cuanto a la enseñanza del francés para fines específicos, turismo en nuestro caso, la labor del docente debe incidir en mostrar los estereotipos de la nueva lengua cultura ayudándoles a reflexionar y a superar los matices, excepciones y singularidades que pudieran presentarse pues ninguna cultura del mundo puede quedar reducido a unas pocas imágenes estereotipadas ya que perdería una parte importante de su esencia. La competencia intercultural proporciona generalidades basadas en observaciones e investigaciones

${ }^{4}$ El término estereotipo fue acuñado por Walter Lippmann (1922) durante la década de 1930. El sentido que el autor le dio al vocablo fue para simbolizar las imágenes que las personas tienen en su mente. Estereotipar a un individuo o grupo significa reducir el resto de sus cualidades a una imagen general sobre todos aquellos que entren en dicho molde.

${ }^{5}$ Con respecto al sector turístico, el estereotipo ha sido, a menudo, el leitmotiv de las promociones turísticas véase, a modo de ejemplo toda la publicidad que sea hecho a través de folletos, cuñas publicitarias, páginas web,... Sólo bastaría recordar algunas campañas publicitarias de décadas pasadas donde los elementos destacables de España eran, en exclusiva, el sol, las corridas, los toros, la fiesta,... y dejando en un segundo o tercer plano la literatura, la arquitectura, los diferentes paisajes naturales,... por temor, tal vez, a perder la gran afluencia turística. En definitiva, este país desde el punto de vista turístico se ha vendido y aún se sigue vendiendo, en algunas ocasiones, a Europa y al mundo a través de sus estereotipos. 
cuidadosas y se las ofrece a la gente como simples pautas de un país o de una cultura superando, de este modo, los estereotipos. Intenta, en definitiva, erradicar ideas o imágenes preconcebidas a través del dialogo y la discusión. Con relación a nuestros manuales, quisiéramos puntualizar que la presencia en éstos de estereotipos no están vetados pues como ya hemos señalado más arriba algunos pueden ser positivos para conocer una nueva lengua-cultura siempre que se indique que son imágenes preconcebidas positivas o negativas y que es necesario traspasar los límites de esa superficialidad que nos transmiten los estereotipos.

\section{RELACIÓN DE LOS COMPONENTES QUE INTEGRAN LOS MANUALES DE FRANCÉS PARA EL TURISMO}

Antes de adentrarnos en verificar si los parámetros interculturales figuran en nuestro corpus de análisis elegido, pensamos que sería pertinente iniciar nuestra investigación con la exposición de los principales elementos que configuran dichos manuales. Para este propósito hemos optado por los componentes que les unen, es decir, elementos coincidentes entre ellos como son, por ejemplo, los temas turísticos tratados, la ilustración de los temas (textos auténticos, fotos,...), los aspectos gramaticales coincidentes con el tema, las tareas comunicativas, ...

Para dicho propósito, hemos elaborado una parrilla de análisis en la que hemos incluido todos los componentes que forman parte de estos libros de textos. Ésta nos va a permitir visualizar, en un primer momento, si los tres manuales elegidos para este análisis son similares en cuanto a los temas abordados y su desarrollo. En nuestra parrilla hemos incluido los siguientes elementos:

Tabla 1. Componentes de los manuales de francés para el turismo

\begin{tabular}{|c|c|c|c|}
\hline & LMT* & LFT & TC \\
\hline TEMAS & $v$ & $\checkmark$ & $v$ \\
\hline TEXTOS AUTÉNTICOS Y PROFESIONALES & $v$ & $\checkmark$ & $v$ \\
\hline IMÁGENES & $v$ & $\checkmark$ & $v$ \\
\hline TAREAS COMUNICATIVAS & $v$ & $v$ & $v$ \\
\hline EXPLICACIONES GRAMATICALES & $\mathrm{v}$ & $\mathrm{v}$ & $\mathrm{v}$ \\
\hline RESÚMENES GRAMATICALES & $v$ & $\checkmark$ & $v$ \\
\hline EJERCICIOS GRAMATICALES & v & v & $\mathrm{v}$ \\
\hline
\end{tabular}




\subsection{Observaciones y análisis del resultado de la parrilla}

En un primer momento, al analizar nuestra parrilla, advertimos que los tres manuales coinciden plenamente entre ellos pues aparentemente todos están estructurados de forma similar. Sin embargo, en el apartado denominado «Temas» a pesar de que los tres manuales se componen de seis bloques temáticos donde cada bloque incluye una serie de unidades que pueden ser variables, por ejemplo en LMT, el bloque 1 tiene tres unidades pero el bloque 2 tiene 6 unidades, es decir, los tres manuales carecen de una estructura fija en cuanto al número de unidades. Creemos que esto se puede deber al nivel de lengua de cada manual pues constatamos que la mayor división en unidades corresponde a turisme.com cuyos destinatarios son estudiantes de nivel A1. En los otros dos manuales, la división en unidades es claramente menor. Por lo tanto, el nivel de lengua de los manuales marca una diferencia significativa en la manera de abordar cada uno de los temas propuestos. Todos tratan temas turísticos tales como los transportes, la agencia de viajes, la promoción turística, la venta de un producto turístico, la animación, la hostelería ${ }^{6}$ pero la diferencia entre ellos viene expresada por el nivel de lengua del manual. En definitiva, la divergencia la encontramos en la profundización de cada unos de los bloques temáticos. El nivel de lengua es el elemento que va a señalar las pautas no sólo en cuanto a la presentación de los distintos temas sino también en cuanto a los documentos auténticos utilizados, las explicaciones gramaticales, las tareas comunicativas. A modo de ejemplo, presentamos a continuación tres documentos auténticos sobre el mismo eje temático «Les transports» - « Indicateur Horaire» - «l'avion».

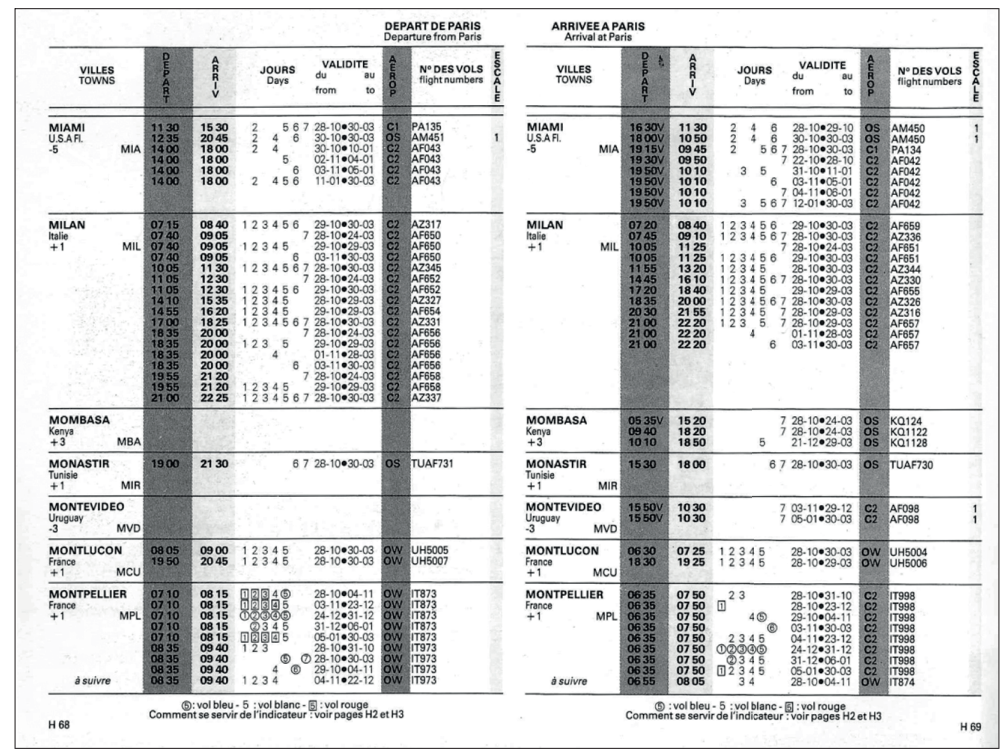

Figura 4. Indicador horario 1.

${ }^{6}$ En el manual tourisme.com el tema de la hostelería y restauración no aparecen porque los mismos autores han creado un manual específico para dichos temas: Hôtellerie-Restauration.com 
El indicador horario 1 que corresponde al manual LMT (A2+) nos presenta un texto auténtico que corresponde a una información real. Como se puede apreciar, es un texto de dificultad media con una gran carga de información que implica, en cierto modo, que el estudiante ya posee una cierta familiarización con este tipo de texto pues, éste no ha sido simplificado: las notas que aparecen en la parte inferior del documento van dirigidas al viajero y no al estudiante.

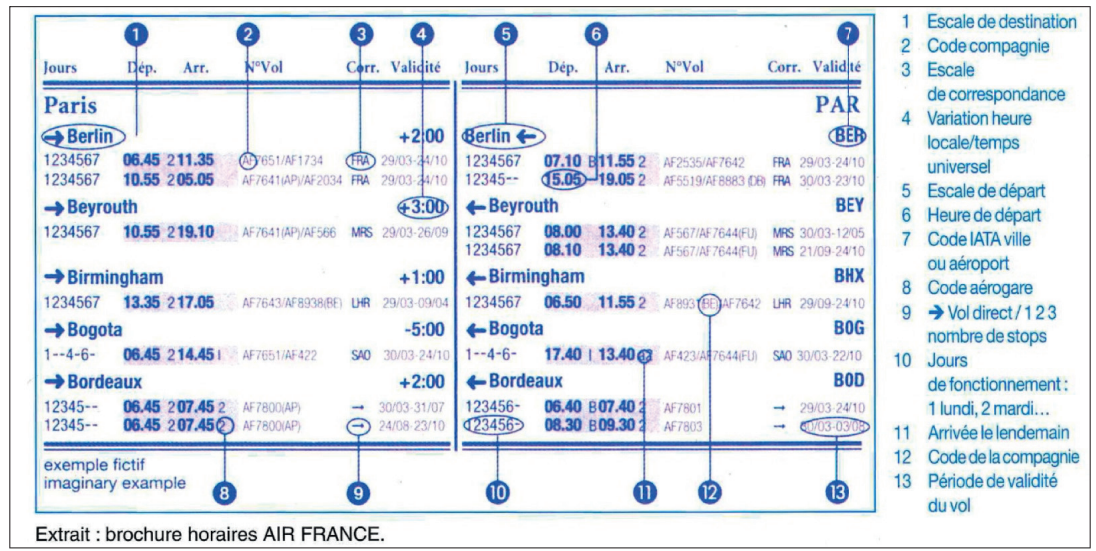

Figura 5. Indicador horario 2.

En el indicador horario 2 que corresponde al manual LFT (A2) nos presenta igualmente un texto auténtico y, por lo tanto, corresponde a una información real. Sin embargo, en este documento, ya encontramos una ligera diferencia con respecto al texto anterior en la medida en que la información no está tan saturada y aparecen elementos explicativos para el estudiante que viene representado por una numeración del 1 a 13 en la parte izquierda del documento donde se explican los componentes del cuadro horario. Por lo tanto, el documento auténtico se ajusta al nivel de lengua del manual.

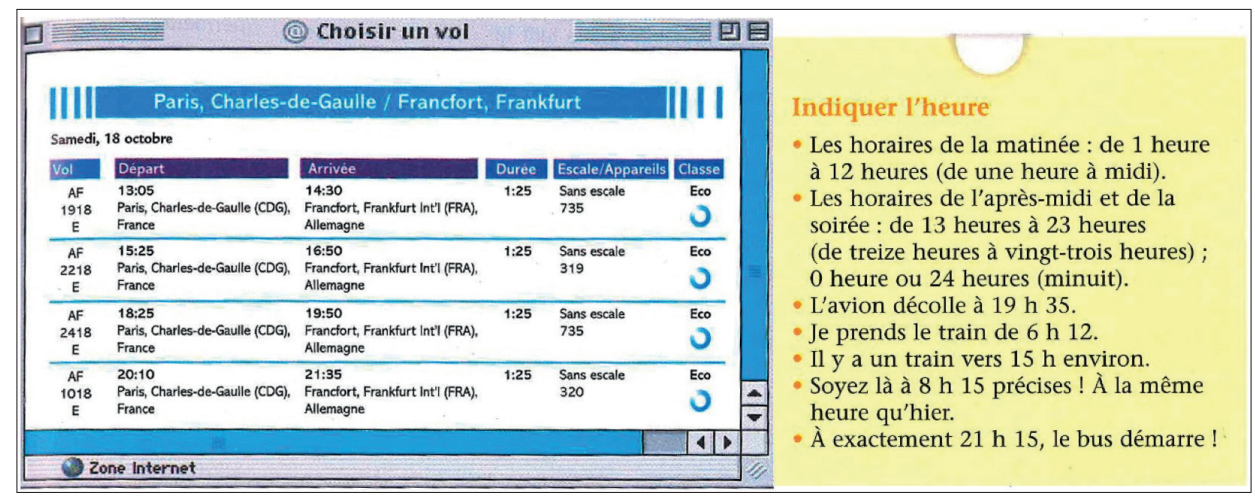

Figura 6. Indicador horario 3. 
En el indicador horario 3 que corresponde al manual TC (A1) estamos, al igual que en los dos anteriores, ante un documento auténtico pero mucho más simplificado desde el punto de vista de información y extensión (documento corto y breve). La dificultad léxica corresponde, al igual que en los dos ejemplos anteriores al nivel de lengua del manual.

Estos documentos auténticos presentados vienen a ejemplarizar la estructuración de estos tres manuales en cuanto a sus temas y documentos. Si nos detenemos en las tareas específicas propuestas ${ }^{7}$ llegamos a la misma observación, es decir, que el único elemento diferenciador existente entre ellos no es otro que su nivel lingüístico pues las actividades en torno a este tema son prácticamente similares: responder a una serie de preguntas en relación al cuadro horario propuesto.

A modo de conclusión, estamos en condiciones de afirmar que la estructura de estos manuales y sus contenidos tienen un grado de equivalencia significativa ${ }^{8}$. Creemos que su similitud no responde a una casualidad en la medida en que en los manuales Les Métiers du Tourisme y Le Français du Tourisme, a pesar de que les separa un poco más de una década, comparten un «avant-propos» respaldado por la Cámara de Comercio e Industria de París, sede de los exámenes de $\mathrm{CFTH}^{9}$ y, por otro lado, en Les Métiers du Tourisme y tourisme.com comparten autoras, a saber: Sophie Corbeau y Chantal Dubois. Todas estas conexiones entre ellos vienen a reforzar la semejanza existente en este corpus de análisis.

\subsection{Verificación de los tres parámetros en nuestro corpus de análisis}

Como ya hemos mencionado anteriormente en este artículo ${ }^{10}$, el enfoque eminentemente práctico y activo debe presidir la enseñanza-aprendizaje de un idioma con fines específicos, en nuestro caso francés para el turismo, y la plena inserción de la utilización concreta del idioma en la práctica profesional han de dar una especial relevancia a la selección y al desarrollo de los contenidos y los recursos que debe integrar un manual de esta índole. Asimismo, opinamos que los tres parámetros interculturales mencionados en el apartado 2.1. han de incluirse en cualquier manual de lenguas extranjeras para fines específicos para poder alcanzar un grado óptimo de conocimiento profesional.

Retomando, pues nuestros tres parámetros: la inclusión de la identidad, la comparación de las dos lenguas-culturas y la eliminación de la jerarquización y la verificación de los estereotipos y su superación en ambas lenguas-culturas comprobamos que éstos no aparecen representados en ningún de nuestros manuales. Ni una sola mención a las dos lenguas culturas, en nuestro caso Francés/Español y, por lo tanto, ninguna similitud o diferencia entre ambas lenguas/culturas ni estereotipos. Todos los bloques temáticos se enmarcan dentro de un ámbito geográfico reducido e incluso exclusivo a Francia obviando, de este modo, todos los países

\footnotetext{
7 Véase anexo 1

${ }^{8}$ Quisiéramos señalar que el manual Les Métiers du Tourisme presenta todos los bloques temáticos en blanco y negro incluyendo textos, documentos y fotos. Este aspecto hace que este manual pueda resultar, en ocasiones, poco atractivo para el estudiante. Sin embargo, en los otros dos manuales, el color predomina en su totalidad.

${ }^{9}$ Certificat de Français du Tourisme et de 1’Hôtellerie.

${ }_{10}$ Apartado 3
} 
pertenecientes al mundo de la francofonía pues no se encuentra en ellos ninguna referencia al sector turístico de, por ejemplo, Bélgica, Luxemburgo, ... y mucho menos aún de las islas de ultramar (La Martinique, La Guadeloupe, ...). Por supuesto, en dichos manuales no aparece tampoco ninguna referencia al entorno turístico y social de otros países de lenguas y culturas diferentes. Esto no lleva a deducir que nuestro corpus, así como la mayoría de los manuales FOS, no están contextualizados, no se hacen pensando en un público determinado pero en destinatarios plurales, es decir, un mismo manual FOS sirve tanto para estudiantes españoles, ingleses como italianos y otros, obviando, de este modo, el aspecto intercultural de cada uno de estos países. No existe, por lo tanto, interacción entre las culturas.

A modo de conclusión, podríamos decir que los manuales que acabamos de presentar encauzan la enseñanza-aprendizaje de FOS desde un punto de vista unilateral donde sólo e exclusivamente se presentan la cultura y sociedad francesa en un entorno turístico sin tener en cuenta ningún elemento sociocultural del aprendiz. Nos muestran una visión del contexto turístico, a menudo, sesgada, estereotipada y parcial. En cada uno de estos manuales predomina, por un lado, la tendencia a la persistencia de la tradición centralista desde el punto de vista geográfico preferentemente la capital (París) frente a las provincias y, por otro lado, al turismo de las grandes ciudades con sus monumentos representativos frente al turismo regional, rural y, finalmente, a la omisión prácticamente total del sector turístico en los países francófonos o de ultramar. Al hilo de esta última observación, sorprende que en los documentos auténticos (folletos turísticos, itinerarios, complejos hoteleros,..) que aglutinan estos manuales no se encuentre ninguno que haga referencia a los países que conforman la francofonía.

\section{CONCLUSIÓN}

El análisis que hemos realizado de estos tres manuales FOS nos ha permitido llegar a una serie de conclusiones que vamos a plasmar a continuación. El primer elemento que queremos resaltar es que ninguno de estos libros de texto están contextualizados, es decir, el público al que va destinado no es exclusivamente español por lo tanto, los parámetros interculturales quedan excluidos ya que solo éstos tienen cabida dentro de un marco que permita aprender «al otro» desde su cultura. Asimismo, somos de la opinión de que cualquier material didáctico intercultural nunca puede ser universal debido esencialmente a su componente sociocultural y a la comunicación de doble vía.

Otro aspecto relevante que hemos podido observar en este análisis y que se deriva del primero es que al carecer o omitir la otra realidad cultural, estos manuales se convierten en limitados y herméticos de una sola cultura, en este caso francés, sin la más mínima referencia a otras vidas, culturas. Parece, cuanto menos sorprendente, que ni siquiera el mundo francófono o los países de ultramar tengan un espacio en estos libros de texto. Este segundo elemento aleja los parámetros interculturales en la medida en que éstos permiten aprender « al otro» desde su cultura, dialogar, debatir y poner en práctica la cooperación y la convivencia. Rodrigo Alsina (1999) indica, al respecto, que la interculturalidad envuelve diálogo crítico y autocrítico y la comunicación entre los que son diferentes (personas y grupos). 
Finalmente, en estos manuales, el aspecto cultural queda relegado a un segundo e incluso tercer plano. Además, ningún documento auténtico hace referencia a elementos socioculturales de ese país, Francia. En realidad, estamos ante tres manuales generalistas con pinceladas de contenido y vocabulario turísticos. Por lo tanto, solamente se diferencian de cualquier manual al uso de francés por el nombre de cada uno de sus bloques temáticos que siempre alude al sector turístico.

A modo de conclusión, quisiéramos indicar que en cualquier manual FOS, la cultura ha de figurar en igualdad de condiciones que los aspectos morfosintácticos de la lengua meta pues tanto uno como el otro son determinantes para alcanzar un aprendizaje intercultural óptimo y adquirir las destrezas necesarias para desenvolverse satisfactoriamente dentro del sector turístico. Los contenidos interculturales, bajo nuestro punto de vista, deben de estar presente en todos y cada uno de los manuales FLE y FOS pero, en éstos últimos, dichos contenidos son imprescindibles en la medida en que éstos aportan un valor añadido. Los aspectos culturales en la enseñanza del francés para fines específicos son fundamentales para adquirir las competencias necesarias para poder desarrollarse de manera óptima dentro del sector profesional turístico. Algunos autores como (Llobera 2000), en el caso de los negocios (Juárez 2005; Sabater 2004; Calvi 2003) o el turismo (Calvi 2005) al referirse al español para fines específicos y perfectamente extrapolable a FOS, sostienen que los contenidos culturales en la enseñanza son fundamentales para adquirir la competencia plena y desarrollar estas actividades en el seno de la sociedad de la lengua meta.

Por último, no sería descabellado afirmar que los manuales para fines específicos analizados no han dedicado la atención que debiera al proceso intercultural y no lo han tratado con la importancia que requiere.

\section{BIBLIOGRAFÍA}

Beacco Jean-Claude, Michael Byram, Marisa Cavalli, Daniel Coste, Mirjam Egli Cuenat, Francis Goullier Et Johanna Panthier (2010): Guide pour le développement et la mise en ouvre de curriculums pour une éducation plurilingue et interculturelle, Strasbourg: division des politiques linguistiques, Direction de l'Éducation et des langues, Conseil de l'Europe.

Byram, Michael y Michael Fleming (2001): Perspectivas interculturales en el aprendizaje de idiomas, Madrid, Cambridge University Press, p.14.

Calmy, Anne Marie (2004): Le Français du Tourisme, París, Hachette.

Calvi, María Vittoria (2001): «El español del turismo: Problemas didácticos». En F. Luttikhuizen (Ed.). IV congrés internacional sobre llengües per a finalitats específiques. The language of international communication. Español de los negocios. Barcelona: Universitat de Barcelona, pp. 299-303.

- (2003): «El componente cultural en la enseñanza del español para fines específicos», II Congreso Internacional de Español para Fines Específicos, Amsterdam, p.117.

- (2005): «El español del turismo: problemas didácticos», Ideas (FH-Heilbronn), 1, marzo de 2005, http:// ideas-heilbronn.org/artic.htm (12-05-2014).

Carras, Catherine, Jacqueline Tolas, Patricia Kohler y Elisabeth Szilagyi (2007): Le Français sur objectifs spécifiques et la classe de langue. París, Clé International, p.21.

Centro Virtual Cervantes (2011): «Enseñanza de la lengua para fines específicos», Diccionario de términos clave de ELE: http://cvc.cervantes.es/ensenanza/biblioteca_ele/diccio_ele/diccionario/ensenanzafinesespec. htm (16-05-2014), p.1.

Chantelouve, Odile, Sophie Corbeau y Chantal Dubois (1991): Les Métiers du Tourisme, Paris, Hachette. 
Choppin, Alain (1980): «L'histoire des manuels scolaires. Une approche globale», Histoire de l'éducation, n. ${ }^{\circ} 9$, pp. 1-25.

CONSEJo DE EuRopa (2002): Marco común europeo de referencia para las lenguas: aprendizaje, enseñanza, evaluación, Estrasburgo: http://cvc.cervantes.es/ensenanza/biblioteca_ele/marco/cvc_mer.pdf (18-07-2014), p.155.

Corbeau Sophie, Chantal Dubois Et Jean-Luc Penfornis (2004): tourisme.com. París, Clé International.

Dale, Gillian y Helen Oliver (2000): Travel \& tourism, London, Hodder \& Stoughton.

HERRERO, JUAN (2006): «La teoría del estereotipo aplicada a un campo de la fraseología: las locuciones expresivas francesas y españolas»: http://www.ucm.es/info/especulo/numero32/teoreste.html (11-09-2014).

JuÁRez Medina, ANTONio (2005): «Competencias lingüísticas e interculturales: tendencias actuales en las empresas alemanas» en IDEAS-Revista electrónica (FH- Heilbronn) n. ${ }^{2}$, pp. 8-19: http://ideas-heilbronn.org/artic.htm (06-10-2014).

Korstanje, Maximiliano (2011): «QQué es el Turismo?», Revista de Investigación en Turismo y Desarrollo Local, febrero 2011: http:// http://www.eumed.net/rev/turydes/09/kem.pdf (07-08-2014), p.1.

Lamo de Espinosa, Emilio (1993): «La mirada del otro. La imagen de España en el extranjero», Información Comercial Española, n. ${ }^{\circ} 722$, Madrid, p.13.

Lippmann, Walter (1922): Public opinion, New York, Harcourt Brace.

Llobera, Miquel (2000): «Aspectos semióticos del discurso en la enseñanza de EpFE. Ideaciones y dimensión educativa», I Congreso Internacional de Español para Fines Específicos. Conferencia de apertura. http://cvc. cervantes.es/ensenanza/biblioteca_ele/ciefe/pdf/01/cvc_ciefe_01_0005.pdf (11-09-2014).

Melero Abadía, Pilar (2000): Métodos y enfoques en la enseñanza-aprendizaje del español como lengua extranjera, Madrid, Edelsa-Tandem.

Moreno García, Concha (2000): «Conocerse para respetarse. Lengua y cultura, ¿elementos integradores?», en Aguirre Romero (ed), Espéculo, Universidad Complutense: http://www.ucm.es/info/especulo/ele/moreno.html (21-06-2013), p.1.

PARIcio TAto, María Silvina (2005): «La dimensión cultural en los libros de texto de lenguas extranjeras: pautas para sus análisis», Glosas didácticas n. ${ }^{\circ}$ 15: http://www.um.es/glosasdidacticas/GD15/gd15-13.pdf (18-082014).

Porcher, Louis (2004): L'enseignement des langues étrangères, Paris, Hachette Livre, p.118.

Rodrigo Alsina, Miquel (1999): Comunicación intercultural, Barcelona, Anthropos.

Sabater, María Lluisa (2004): «Necesidad de reflexión sobre la diversidad cultural en la formación de profesores de español para los negocios», Revista RedELE: http://www.mec.es/redele/revista/index.shtml (19-08-2013).

Suárez, Juan Pedro y Susanne Moss (2000): «La spécificité du discours dans le secteur touristique: Recherche sur les variabilités et les régularités du discours touristique». En II encuentro de profesores de formación turística universitaria. Madrid: ANESTUR: p. 63.

Tagliante, Christine (1994): La classe de langue, Paris, Clé International, p. 68.

Wallerstein, Emmanuel (1992): «Culture as the Ideological Battleground of the Modern World-System», en Mike Featherstone (ed.), Global Culture, London, Sage Publications, pp. 31-55. 


\section{ANEXO 1}

\section{Apprenez à consulter un indicateur horaire}

En consultant la page de l'indicateur des Aéroports de Paris reproduite ci-contre, dites si les affirmations suivantes sont vraies. Eventuellement, rectifiez:

- Le dimanche 24 mars, il y a six vols Milan-Paris.

- Tous les vols pour Miami durent huit heures.

- Tous les vols Paris-Milan sont directs.

- Tous les vols en provenance de Montpellier atterrissent à l'aéroport Charles-de-Gaulle - aérogare 2.

- Ce calendrier est valable toute l'année.

- Ce calendrier concerne seulement les vols en direction de l'Europe.

- Un passager désirant bénéficier d'une réduction sur un vol Montpellier-Paris pourra voyager le lundi 18 mars.

- En février, il y a deux vols hebdomadaires au départ de Mombasa pour Paris.

- Le vol AF 098 au départ de Montevideo pour Paris part le dimanche.

- La liste des horaires est consultable sur Minitel.

- Le 29-3, le dernier vol Paris-Milan est à 19h 55.

\begin{tabular}{|c|c|c|}
\hline & VRAI & FAuX \\
\hline 1. Tous ces horaires concernent des vols au départ de Paris. & 口 & $\square$ \\
\hline 2. Cet indicateur horaire concerne plusieurs compagnies aériennes. & ם & $\square$ \\
\hline 3. Entre le 29 mars et le 26 septembre, il y a un vol Paris-Beyrouth. & ם & $\square$ \\
\hline 4. Le vol Paris-Bogota est direct. & ם & $\square$ \\
\hline 5. Il y un décalage horaire entre Berlin et Bordeaux. & $\square$ & $\square$ \\
\hline 6. Le vol direct AF7803 Bordeaux-Paris fonctionne le mercredi. & ם & $\square$ \\
\hline
\end{tabular}

A. Observez la fiche horaire d'Air France et répondez aux questions.

1. Quelle est la date du départ ? Et celle d'arrivée ?

2. À quelle partie de la journée les horaires de départ se rapportent-ils ?

3. À quelle partie de la journée les horaires d'arrivée se rapportent-ils ?

4. Combien de vols France-Allemagne sont proposés à l'écran?

5. Quels sont les aéroports indiqués?

6. Quel est le temps de vol du AF 2218?

7. À votre avis, que veut dire l'indication " $E$ "? 